\title{
Receptor-like kinase complexes in plant innate immunity
}

\section{Christiaan Greeff, Milena Roux, John Mundy and Morten Petersen*}

Department of Biology, Copenhagen University, Copenhagen, Denmark

\section{Edited by:}

Jacqueline Monaghan, The Sainsbury Laboratory, UK

Reviewed by:

Pascal Braun, Technical University of Munich, Germany

Lennart Wirthmueller, John Innes

Centre, UK

\section{${ }^{*}$ Correspondence:}

Morten Petersen, Department of

Biology, Copenhagen University,

Biocenter 3.1.45, Ole Maaløes Vej 5,

Copenhagen, Denmark.

e-mail: shutko@bio.ku.dk
Receptor-like kinases (RLKs) are surface localized, transmembrane receptors comprising a large family of well-studied kinases. RLKs signal through their transmembrane and juxtamembrane domains with the aid of various interacting partners and downstream components. The N-terminal extracellular domain defines ligand specificity, and RLK families are sub-classed according to this domain. The most studied of these subfamilies include those with (1) leucine-rich repeat (LRR) domains, (2) LysM domains (LYM), and (3) the Catharanthus roseus RLK1-like (CrRLK1L) domain. These proteins recognize distinct ligands of microbial origin or ligands derived from intracellular protein/carbohydrate signals. For example, the pattern-recognition receptor (PRR) AtFLS2 recognizes flg22 from flagellin, and the PRR AtEFR recognizes elf18 from elongation factor (EF-Tu). Upon binding of their cognate ligands, the aforementioned RLKs activate generic immune responses termed pattern-triggered immunity (PTI). RLKs can form complexes with other family members and engage a variety of intracellular signaling components and regulatory pathways upon stimulation. This review focuses on interesting new data about how these receptors form protein complexes to exert their function.

Keywords: receptor-like kinases, complexes, plant immunity, signaling, defense

\section{INTRODUCTION}

Autotrophs, like plants, are the source of nutrients for heterotrophs. Plants are members of complex communities and have co-evolved commensal and pathological relationships with microbes. A fine balancing act is required to effectively combat invasion by pathogenic heterotrophs while effectively guarding resources for vegetative and reproductive growth (King and Roughgarden, 1982). This entails appropriately timed activation of defense responses to conserve energy for producing numerous healthy progeny, thus increasing evolutionary fitness through this adaptive plasticity (Sultan, 2000). Detecting harmful heterotrophs and converting this recognition to intracellular signals aimed at combating the intruder and alerting surrounding tissue, is a major challenge, especially since pathogens co-evolve with their hosts to elude discovery (Frank, 1992; Lehti-Shiu et al., 2009).

Plant genomes encode a large number of surface receptorlike kinases (RLKs) to perceive different signals from both distal cells responding to stresses such as herbivore feeding or to the presence of pathogens through detection of non-self molecules (Shiu and Bleecker, 2001). RLKs generally have an extracellular ligand-binding domain, a membrane-spanning region, a juxtamembrane (JM) domain, and a serine/threonine kinase domain. Equivalent mammalian receptors from the Pelle/IRAK family differ in usually employing a cytosolic tyrosine kinase domain (Gish and Clark, 2011). A conserved aspartate in the catalytic loop of most kinases is required for catalytic activity. Ser/Thr kinases mostly have an arginine preceding this catalytic aspartate. Kinases with such residues are termed RD kinases, although most RLKs implicated in microbial detection are non-RD kinases, lacking an arginine preceding the catalytic aspartate. They in general require additional proteins to modulate their function (Johnson etal., 1996; Dardick and Ronald,
2006). An important example is BAK1, which interacts with many Arabidopsis RLKs, and is required for their activity (discussed below).

The plant RLK family has more than 600 members in Arabidopsis (Shiu et al., 2004). RLKs are divided into 44 sub-families depending on their N-terminal domains. While RLKs have been implicated in many biologically important processes (Gish and Clark, 2011), this review focuses on RLKs involved in pathogen detection.

Plant RLKs involved in immunity are so-called patternrecognition receptors (PRRs) that detect pathogen-associated molecular patterns (PAMPs) and, upon binding of their cognate elicitors, initiate a well-characterized set of defense responses termed PAMP-triggered immunity (PTI). Features of PTI include reactive oxygen species (ROS) production, callose deposition, generation of secondary messengers, and defense gene expression (Jones and Dangl, 2006). RLK elicitation also leads to activation of several mitogen-activated protein (MAP) kinases (Suarez-Rodriguez et al., 2007; Mithoe et al., 2011). PAMPs, and more broadly, microbial-associated molecular patterns (MAMPs) and damage-associated molecular patterns (DAMPs), can activate RLKs (Lerouge et al., 1990; Gómez-Gómez and Boller, 2000; Zipfel et al., 2006; Krol et al., 2010). Binding of PAMPS and DAMPS to their specific receptors leads to a broad range of downstream signaling events and effects. Figures $1 \mathrm{~A}-\mathrm{C}$ gives an overview of some of the complexes of Xa21, FIS2, and EF-Tu receptor (EFR) that will be discussed in this review. Figure 1D shows biological effects of FLS2, Xa21 and EFR.

\section{THE LRR FAMILY}

The best-studied members of the leucine-rich repeat (LRR)-RLK family are the non-RD kinases AtFLS2, AtEFR, and OsXa21 (Park 

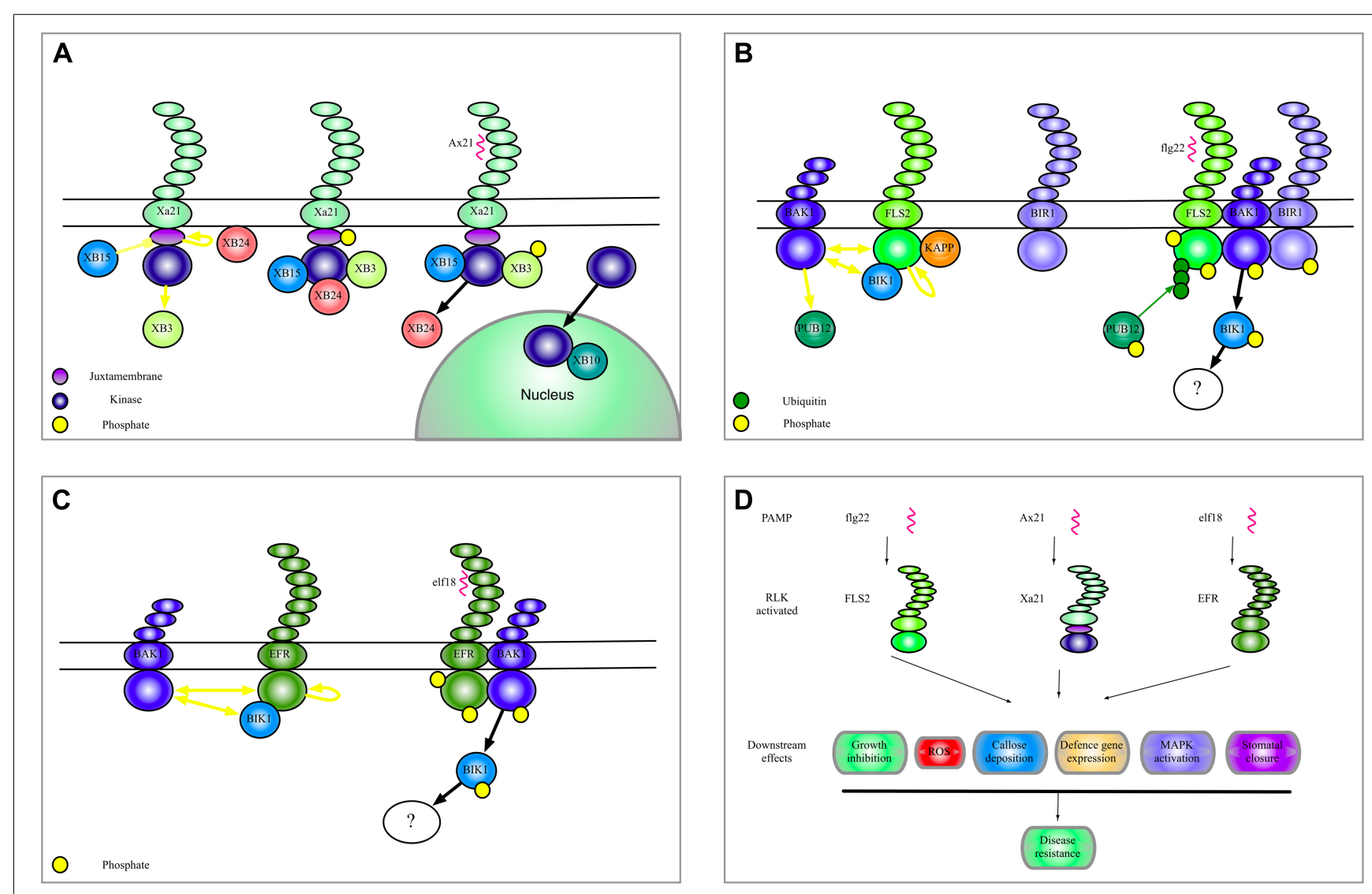

FIGURE 1 | Complexes of Xa21, FLS2, and EFR. (A) A model to summarize the current data regarding $\mathrm{Xa} 21$ function as discussed in this manuscript. (B) Illustration of the complexes formed by the RLK-FLS2. The yellow dots indicate phosphorylation of a protein. Yellow arrows indicate phosphorylation of a substrate protein. Yellow

etal., 2010a) and the RD kinase BAK1 (Chinchilla et al., 2007; Heese et al., 2007). These receptors present the core of our current knowledge regarding RLKs involved in defense.

\section{Xa21}

The Xa21 extracellular domain is composed of 23 LRRs and was one of the first eukaryotic RLKs found to be involved in resistance (Song et al., 1995; Wang et al., 2006). Xa21 binds the Xanthomonas oryzae pv. oryzae (Xoo) secreted tyrosine (Tyr) O-sulfonation peptide $\mathrm{AxY}^{\mathrm{S}} 22$ (Lee et al., 2009). Much has been learned about the function of Xa21. For example, the amino acids Ser686, Thr688, and Ser689 in the cytosolic JM domain are important for stability and for endoplasmic reticulum (ER) processing (Xu et al., 2006; Park et al., 2010a). Phosphorylation of residues in the JM domain is also critical for the activation of Xa21 and binding of at least four Xa21-binding proteins named XB3, XB15, XB24, and XB10 (OsWRKY62; Park et al., 2010b) associated with Xa21 via the JM domain. These interactions are all dependent on Thr705 since mutation of this JM domain residue abolishes XB-Xa21 binding (Chen et al., 2010a).

$\mathrm{XB} 3$ is an E3 ligase important for Xa21 accumulation and is a substrate for Xa21 kinase activity, although the biological relevance blunt arrows indicate dephosphorylation of a substrate protein. Green dots and green arrows indicate ubiquitination. Black arrows indicate translocation, association or dissociation. (C) Selected interactors of the RLK EFR. (D) Shows biological effects of selected RLK activation. of this relationship is still unclear. After Xa21 binds $\mathrm{AxY}^{\mathrm{S}} 22$, XB3 is activated by transphosphorylation and likely leads to cleavage of a negative regulator of defense or even of itself, allowing other interactions to take place (Wang et al., 2006).

$\mathrm{Xa} 21$ is regulated by two proteins through phosphorylation; $\mathrm{XB15}$, a protein phosphatase $2 \mathrm{C}$ (PP2C) and XB24, a protein with intrinsic ATPase activity (Park et al., 2008). XB15 dephosphorylates Xa21 and XB15 over-expression reduces Xoo resistance while $x b 15$ null-mutants exhibit increased cell death and resistance to Xoo. This would point to a negative regulatory role of XB15. On the other hand, XB24 promotes autophosphorylation of Xa21 and may be required to prevent proteolytic cleavage of Xa21. The complex between XB24 and Xa21 dissociates upon Xoo infection or $\mathrm{AxY}^{\mathrm{S}} 22$ binding (Chen et al., 2010b). Phosphorylation, especially in the JM domain, plays a critical role in Xa21 stability. It is clear that autophosphorylation of certain residues in Xa21 promotes an inactive state but the exact changes in phosphorylation status upon pathogen infection remain largely unknown.

$\mathrm{Xa} 21$ binds to the WRKY transcription factor XB10 and this binding requires an active Xa21 kinase domain. Binding of the $\mathrm{AxY}^{\mathrm{S}} 22$ peptide to Xa21 leads to translocation of a Xa21 kinase domain-GFP fragment to the nucleus where it interacts with XB10. 
The nuclear translocation is important for Xoo resistance and the Xa21 kinase domain/XB10 complex probably affects defense gene expression (Park and Ronald, 2012). Whether this or a similar mechanism also applies to other RLKs is currently unknown, but future studies will likely address this issue. Recently, a largescale yeast two-hybrid study revealed yet another set of Xa21 interacting partners (Seo et al., 2011). Although the biological significance of these discoveries in signaling remains to be seen, they may provide interesting clues to the functions of Xa21 and other RLKs.

To help proteins fold properly, the ER contains a number of chaperones including BiPs (binding immunoglobulin protein) that bind $\mathrm{N}$-glycosylated proteins and direct them to the ER (Molinari and Helenius, 2000). Xa21 is also N-glycosylated and interacts with $\mathrm{BiP} 3$, an HSP70-like ATPase located in the ER, and this is important for correct folding and functioning of the protein (Park et al., 2010a). While a pool of Xa21 locates to the PM where AxYS22 ligand is perceived, the majority of the receptor is found in the ER.

\section{AtFLS2}

The FLS2 (flagellin sensing 2) receptor recognizes the wellconserved protein flagellin from a broad class of bacterial plant pathogens including Pseudomonas syringae pv. tomato (Pto) DC3000 (Gómez-Gómez and Boller, 2000). Direct binding of the flagellin-derived peptide flg22 has been shown using ${ }^{125}$ I-labeled peptides (Chinchilla et al., 2006), but a recent report also implicates FLS2 in unsulfonated Xoo Ax21 peptide perception. These two peptides are not sequence related, which makes the finding quite astonishing (Danna et al., 2011).

FLS2 was recently shown to form homo-dimers independently of flg22 binding, but whether this dimerization is important for receptor function is not known (Sun et al., 2012). However, it is well-established that FLS2 forms heterodimers with BRI1associated kinase 1 (BAK1) (Chinchilla et al., 2007; Schulze et al., 2010) in the presence of bound flg22. BAK1 is a common component in many RLK signaling complexes, and was first identified for its requirement in brassinosteroid signaling via the receptor BRI1 (Li et al., 2002). The essential role of BAK1 in flg22 sensing was revealed by the marked reduction of flg22-induced responses in bak1 plants (Chinchilla et al., 2007; Heese et al., 2007). Importantly, the BAK1-FLS2 interaction most likely does not compete with other known BAK1 interactors such as BRI1, and the BAK1FLS2 interaction is therefore not responsible for BR-mediated PAMP defense suppression (Albrecht et al., 2012). BAK1 is a member of the somatic embryogenesis receptor kinase (SERK) family comprising 5 members, SERK1, SERK2, BAK1/SERK3, BAK1like (BKK1)/SERK4, and SERK5. FLS2 interactions with SERK1, SERK2, SERK5, and BKK have been detected, but its predominant association is with BAK1. BAK1 and BKK1 are thought to act cooperatively in PAMP signaling and resistance to biotrophic pathogens (Roux et al., 2011).

BAK1 and FLS2 also interact with Botrytis-induced kinase 1 (BIK1), which is a receptor-like cytoplasmic kinase (RLCK) implicated in resistance to necrotrophic pathogens (Veronese etal., 2006). BAK1 and FLS2 phosphorylate BIK1 (Lu et al., 2010) and BIK1 in turn phosphorylates both FLS2 and BAK1. This is thought to be an important signal amplification mechanism. However, since FLS2 has been shown to have very low catalytic activity in vitro (Schwessinger et al., 2011), BAK1 probably possesses the predominant kinase activity influencing BIK1 phosphorylation. The BIK1-FLS2/BAK1 association is decreased after flg22 sensing, suggesting that BIK1 is released to activate downstream signaling components (Lu et al., 2010). BIK1's role in PTI is dependent on complex interactions with major immune response regulators and may thus provide RLK signaling complexes with the ability to discriminate between biotrophic and necrotrophic pathogens (Laluk et al., 2011). Importantly, bik1 mutants display enhanced susceptibility to Pto DC3000, reduced flg22 responsiveness, as well as compromised flg22-induced resistance to virulent Pto DC3000. The BIK1-related kinases, PBS-like kinase 1 (PBL1) and PBL2 also interact with FLS2 and BAK1. pbl1 mutants show less reduction in PTI responses but the effect seems to be additive to BIK1 function (Zhang et al., 2010).

BAK1, BKK1, SERK1, and SERK2 have also been shown to interact with BIR1 (BAK1-interacting receptor-like kinase 1), an active protein kinase. The birl mutant exhibits increased resistance to biotrophic Pto DC3000 and Hyaloperonospora arabidopsidis Noco2, due to apparent $R$ protein activation (Wang et al., 2011). The birl phenotype is partially rescued in bir1 pad4 double mutants, and is completely rescued in the birl pad4 sobir (suppressor of bir 1-1) triple mutant. Phytoalexin deficient 4 (PAD4) is one of the critical components required for Toll/interleukin-1 receptor (TIR) R protein signaling. Many constitutively active defense phenotypes that result from activated TIR $\mathrm{R}$ proteins are suppressed by PAD4 loss of function (Wiermer et al., 2005; Palma et al., 2010; Zhang et al., 2012). The aforementioned results thus indicate that the bir1 phenotype is partly dependent upon $\mathrm{R}$ protein activation, although the majority of defense induction in birl occurs through SOBIR1. SOBIR1 is also a RLK, and over-expression of SOBIR1 leads to activation of cell death. SOBIR1 does not function in flg22 sensing and does not interact with BIR1. Exactly how loss of BIR1 activates SOBIR1 is a mystery (Gao et al., 2009), and it is still uncertain whether BIR1 has a role in the PAMP signaling pathway.

Kinase-associated protein phosphatase (KAPP) interacts with the FLS2 kinase domain (Gómez-Gómez and Boller, 2000), and this interaction may be important for receptor endocytosis upon activation as was found for AtSERK1 (Shah et al., 2002). KAPP has also been found in complexes with other RLKs (Williams etal., 1997; Stone etal., 1998) but whether it functions as a general regulator of a broader spectrum of RLKs needs to be explored.

FLS2 also interacts with E3 ligases that polyubiquitinate the receptor after flg22 signaling. FLS2 is subsequently degraded by the proteasome, which might constitute a mechanism for attenuation as has been described for the mammalian Toll-like receptor 4 (TLR4) and TLR9 (Chuang and Ulevitch, 2004). Plant U-Box 12 (PUB12) and PUB13, both E3 ubiquitin ligases, have been shown to be BAK1 phosphorylation targets, and this modification is required for their association with FLS2. This phosphorylation is reminiscent of the previously mentioned Xa21 phosphorylation of XB3. PUB12 and PUB13 control flg22-dependent, proteasome-mediated degradation of FLS2 
(Lu et al., 2011), making this system important for FLS2 signaling attenuation, together with receptor endocytosis (Salomon and Robatzek, 2006).

Despite being a transmembrane protein, FLS2 does not depend critically on $\mathrm{N}$-glycosylation for its function as has been found for EFR (Nekrasov etal., 2009; Saijo et al., 2009; Häweker et al., 2010). However, FLS2 has recently been shown to interact with the reticulon-like proteins RTNLB1 and RTNLB2. RTNLB1/2 are together involved in regulating FLS2 transport from the ER to the plasma membrane (Lee etal., 2011). In addition, stomatal cytokinesis defective 1 (SCD1) was identified by mass spectrometry as an FLS2 interaction partner. Scd1 mutants display SA-dependent enhanced resistance to infection with Pto DC3000, as well as enhanced accumulation of PR1 transcripts and hydrogen peroxide. However, the same mutants are less sensitive to PAMPs, with reduced seedling growth inhibition and ROS production in response to flg22 or elf18 (Korasick et al., 2010).

\section{EF-Tu RECEPTOR}

EF-Tu receptor is a LRR-RLK that recognizes the peptide elf18 from bacterial elongation factor (EF)-Tu. EFR and BAK1 have also been shown to interact in a ligand-dependent manner (Roux et al., 2011). Indeed, many of the signaling components downstream of EFR and FLS2 are shared. While both EFR and FLS2 are capable of associating with all members of the SERK family, BKK1, SERK1, SERK2 have a stronger association with EFR than with FLS2 (Roux et al., 2011). This might allow EFR to avoid pathogen effector action on the single SERKs. Studies of SERK function have been difficult due to their apparent redundancy and the lethality of some double mutants such as serk 1 serk2 and bak1-4bkk1-1 (Colcombet et al., 2005; He et al., 2007). However, the discovery of a novel allele of bak1, bak1-5, enabled study of non-lethal bak1-5 bkk1 double mutants. This revealed that BAK1 and BKK1 act cooperatively in PAMP signaling (Roux et al., 2011; Schwessinger et al., 2011).

BIK1 is phosphorylated upon elf18 and flg22 treatment ( $\mathrm{Lu}$ et al., 2010). Given the many parallels between FLS2 and EFR, it is possible that transphosphorylation of the EFR/BAK1 complex also occurs, although direct proof is still lacking. In contrast to FLS2, but similarly to Xa21, N-glycosylation is critical for EFR function and EFR is subject to ER quality control that requires several chaperones involved in ER-QC for full activity (Häweker et al., 2010).

\section{PEPR1}

In contrast to the three receptors described above, Pep1 receptor 1 (PEPR1) binds AtPep1 (Yamaguchi et al., 2006) a DAMP derived from the precursor gene PROPEP1. PEPR1 and PEPR2 act redundantly to perceive AtPep1. BAK1 was shown to interact with PEPR1 like FLS2 and EFR (Postel et al., 2010). PEPR1 possesses a putative guanylyl cyclase (GC) domain and cGMP production by the purified RLK was shown in vitro (Qi et al., 2010). Interestingly, a GC domain is also present in BRI1 and was shown to have a catalytic function in vitro (Kwezi etal., 2007). This cGMP generated after elicitation may trigger a cyclic nucleotide-activated $\mathrm{Ca}^{2+}$ channel as part of its signaling activity (Ali et al., 2007).

\section{LysM FAMILY}

Chitin elicitor receptor kinase 1 (CERK1) is the best studied Arabidopsis LysM-RLK (Kaku et al., 2006; Miya et al., 2007; Wan et al., 2008), and direct binding of chitin to CERK1 has been detected (Iizasa et al., 2010; Petutschnig et al., 2010). Unlike FLS2 and EFR, CERK1's perception of fungal chitin is BAK1-independent. In rice, Chitin elicitor-binding protein (CeBIP), a LysM domaincontaining protein, associates with OsCerk1 and these proteins function together in a hetero-oligomer receptor complex to elicit chitin signaling in a ligand-dependent manner (Shimizu et al., 2010). Two LysM domain proteins, LYM1 and LYM3, have recently been shown to be important for peptidoglycan (PGN), but not chitin recognition. LYM1 and LYM3 are not functionally redundant, and it has been proposed that LYM1, LYM3 and CERK1 may form a complex or complexes. cerk1 is hypersusceptible to Pto DC3000 and shows reduced sensitivity to PGN, phenocopying lym1/lym3, however CERK1 does not bind to PGN. Further, given the fact that neither LYM1 nor LYM3 contain a cytoplasmic domain, a LYM1/LYM3/CERK1 complex seems likely (Willmann et al., 2011). RLKs often hetero-oligomerize for optimal functioning as seen in the co-operativity of FLS2/BAK1, EFR/BAK1 and PEPR1/PEPR2.

\section{CrRLK1L FAMILY}

Another RLK, FERONIA (FER) was first shown to control pollen tube reception (Escobar-Restrepo et al., 2007). However, the expression of FER throughout the plant suggests a general function not strictly associated with root development or pollen tube reception. Indeed, FER has more recently been shown to aid powdery mildew (PM) penetration into host cells (Kessler et al., 2010) and to be responsible for susceptibility to the oomycete $H$. arabidopsidis (Nibau and Cheung, 2011). It is suspected that FER might play a role in controlling localization of MLO family proteins, known to be important for PM infection (Consonni et al., 2006), as it does for NTA during pollen tube reception. This however still needs to be shown, as well as whether ROS signaling has an effect on MLO localization. Given the many roles of FER it is not surprising to find that it is important for disease resistance as well.

FER appears to exert is signaling functions by controlling ROS production. FER was shown to interact with guanine nucleotide exchange factors (GEFs) that regulate RHO GTPases (RAC/ROPs). RAC/ROP is known play important roles in stressinduced responses. In rice, the binding of a RAC/ROP called Rac GTPase to NADPH oxidases has been characterized, and Rac GTPase was show to be required for PAMP-mediated ROS production (Wong et al., 2007). In Arabidopsis, Rop2 was shown to co-immunoprecipitate with FER. In addition, transgenic plants expressing constitutively active, GTP-bound Rop2 displayed increased ROS production (Cheung and Wu, 2011). This indicates that a FER-GEF-RAC/ROP complex is likely able to effect ROS production. While ROS play a role in root development, there are hints that FER is involved in ROS production during PAMP signaling in leaves. For example, FER is enriched in detergent-resistant membranes (DRMs) after flg22 treatment, and FER shows flg22induced phosphorylation (Benschop et al., 2007). Fer mutants also exhibit enhanced ROS production, and aberrant stomatal responses upon flg22 treatment (Keinath et al., 2010). The increase 
in ROS production in the fer mutant is puzzling given the reduced Rho GTPase activity in this mutant (Duan et al., 2010). The relationship between FLS2 and FER in the control of ROS production is very interesting and should attract attention in the near future.

\section{CONCLUDING REMARKS}

There have been enormous advancements in our knowledge about RLK signaling in the last decade, but many questions still remain unanswered. For example, the link between the PRR receptors

\section{REFERENCES}

Albrecht, C., Boutrot, F., Segonzac, C., Schwessinger, B., GimenezIbanez, S., Chinchilla, D., Rathjen, J. P., De Vries, S. C., and Zipfel, C. (2012). Brassinosteroids inhibit pathogen-associated molecular pattern-triggered immune signaling independent of the receptor kinase BAK1. Proc. Natl. Acad. Sci. U.S.A. 109, 303-308.

Ali, R., Ma, W., Lemtiri-Chlieh, F, Tsaltas, D., Leng, Q., von Bodman, S., and Berkowitz, G. A. (2007). Death don't have no mercy and neither does calcium: Arabidopsis CYCLIC NUCLEOTIDE GATED CHANNEL2 and innate immunity. Plant Cell 19 , 1081-1095.

Benschop, J. J., Mohammed, S., O’Flaherty, M., Heck, A. J. R., Slijper, M., and Menke, F. L. H. (2007). Quantitative phosphoproteomics of early elicitor signaling in Arabidopsis. Mol. Cell Proteomics 6, 1198-1214.

Chen, X., Chern, M., Canlas, P. E., Jiang, C., Ruan, D., Cao, P., and Ronald, P. C. (2010a). A conserved threonine residue in the juxtamembrane domain of the XA21 pattern recognition receptor is critical for kinase autophosphorylation and XA21-mediated immunity. J. Biol. Chem. 285, 10454-10463.

Chen, X., Chern, M., Canlas, P. E., Ruan, D., Jiang, C., and Ronald, P. C. (2010b). An ATPase promotes autophosphorylation of the pattern recognition receptor XA21 and inhibits XA21-mediated immunity. Proc. Natl. Acad. Sci. U.S.A. 107, 8029-8034.

Cheung, A. Y., and Wu, H.-M. (2011). THESEUS 1, FERONIA and relatives: a family of cell wall-sensing receptor kinases? Curr. Opin. Plant Biol. 14, 632-641.

Chinchilla, D., Bauer, Z., Regenass, M., Boller, T., and Felix, G. (2006) The Arabidopsis receptor kinase FLS2 binds flg22 and determines the specificity of flagellin perception. Plant Cell 18, 465-476.

Chinchilla, D., Zipfel, C., Robatzek, S., Kemmerling, B., Nürnberger, T., Jones, J. D. G., Felix, G., and Boller,
T. (2007). A flagellin-induced complex of the receptor FLS2 and BAK1 initiates plant defence. Nature 448, 497-500.

Chuang, T.-H., and Ulevitch, R. J. (2004). Triad3A, an E3 ubiquitinprotein ligase regulating Toll-like receptors. Nat. Immunol. 5, 495-502.

Colcombet, J., Boisson-Dernier, A., Ros-Palau, R., Vera, C. E., and Schroeder, J. I. (2005). Arabidopsis SOMATIC EMBRYOGENESIS RECEPTOR KINASES1 and 2 are essential for tapetum development and microspore maturation. Plant Cell 17, 3350-3361.

Consonni, C., Humphry, M. E., Hartmann, H. A., Livaja, M., Durner, J., Westphal, L., Vogel, J., Lipka, V., Kemmerling, B., Schulze-Lefert, P., Somerville, S. C., Panstruga, R. (2006). Conserved requirement for a plant host cell protein in powdery mildew pathogenesis. Nat. Genet. 38, 716-720.

Danna, C. H., Millet, Y. A., Koller, T., Han, S.-W., Bent, A. F., Ronald, P. C., and Ausubel, F. M. (2011). The Arabidopsis flagellin receptor FLS2 mediates the perception of Xanthomonas Ax21 secreted peptides. Proc. Natl. Acad. Sci. U.S.A. 108, 9286-9291.

Dardick, C., and Ronald, P. (2006). Plant and animal pathogen recognition receptors signal through nonRD kinases. PLoS Pathog. 2, e2. doi: 10.1371/journal.ppat.0020002

Duan, Q., Kita, D., Li, C., Cheung, A. Y., and Wu, H.-M. (2010). FERONIA receptor-like kinase regulates RHO GTPase signaling of root hair development. Proc. Natl. Acad. Sci. U.S.A. 107, 17821-17826.

Escobar-Restrepo, J.-M., Huck, N., Kessler, S., Gagliardini, V., Gheyselinck, J., Yang, W.-C., and Grossniklaus, U. (2007). The FERONIA receptor-like kinase mediates male-female interactions during pollen tube reception. Science 317, 656-660.

Frank, S. A. (1992). Models of plantpathogen coevolution. Trends Genet. $8,213-219$.

Gao, M., Wang, X., Wang, D., Xu, F., Ding, X., Zhang, Z., Bi, D., Cheng,

and production of ROS and activation of MAP kinases is still missing. Nevertheless, a quite comprehensive picture of the route from receptor activation to enhanced defense gene expression has emerged for Xa21 and similar data for FLS2 and EFR are sure to come to light.

\section{ACKNOWLEDGMENTS}

This work was supported by grants to Morten Petersen from the Danish Research Council for Technology and Production (11-106302) and the Strategic Research Council (09-067148).

Y. T., Chen, S., Li, X., and Zhang, Y. (2009). Regulation of cell death and innate immunity by two receptorlike kinases in Arabidopsis. Cell Host Microbe 6, 34-44.

Gish, L. A., and Clark, S. E. (2011). The RLK/Pelle family of kinases. Plant $J$. $66,117-127$.

Gómez-Gómez, L., and Boller, T. (2000). FLS2: an LRR receptor-like kinase involved in the perception of the bacterial elicitor flagellin in Arabidopsis. Mol. Cell 5, 1003-1011.

Häweker, H., Rips, S., Koiwa, H., Salomon, S., Saijo, Y., Chinchilla, D. Robatzek, S., and von Schaewen, A. (2010). Pattern recognition receptors require $\mathrm{N}$-glycosylation to mediate plant immunity. J. Biol. Chem. 285, 4629-4636.

He, K., Gou, X., Yuan, T., Lin, H., Asami, T., Yoshida, S., Russell, S. D., and Li, J. (2007). BAK1 and BKK1 regulate brassinosteroid-dependent growth and brassinosteroid-independent cell-death pathways. Curr. Biol. 17, 1109-1115.

Heese, A., Hann, D. R., GimenezIbanez, S., Jones, A. M. E., He, K., Li, J., Schroeder, J. I., Peck, S. C., and Rathjen, J. P. (2007). The receptor-like kinase SERK3/BAK1 is a central regulator of innate immunity in plants. Proc. Natl. Acad. Sci. U.S.A. 104, 12217-12222.

Iizasa, E., Mitsutomi, M., and Nagano, Y. (2010). Direct binding of a plant LysM receptor-like kinase, LysM RLK1/CERK1, to chitin in vitro. $J$ Biol. Chem. 285, 2996-3004.

Johnson, L. N., Noble, M. E. and Owen, D. J. (1996). Active and inactive protein kinases: structural basis for regulation. Cell 85, 149-158.

Jones, J. D. G., and Dangl, J. L. (2006). The plant immune system. Nature 444, 323-329.

Kaku, H., Nishizawa, Y., IshiiMinami, N., Akimoto-Tomiyama, C. Dohmae, N., Takio, K., Minami, E., and Shibuya, N. (2006). Plant cells recognize chitin fragments for defense signaling through a plasma membrane receptor. Proc. Natl. Acad. Sci. U.S.A. 103, 11086 11091.
Keinath, N. F., Kierszniowska, S., Lorek, J., Bourdais, G., Kessler, S. A., Shimosato-Asano, H., Grossniklaus, U., Schulze, W. X., Robatzek, S., and Panstruga, R. (2010). PAMP (pathogen-associated molecular pattern)-induced changes in plasma membrane compartmentalization reveal novel components of plant immunity. J. Biol. Chem. 285, 39140-39149.

Kessler, S. A., Shimosato-Asano, H., Keinath, N. F., Wuest, S. E., Ingram, G., Panstruga, R., and Grossniklaus, U. (2010). Conserved molecular components for pollen tube reception and fungal invasion. Science 330, 968-971.

King, D., and Roughgarden, J. (1982). Multiple switches between vegetative and reproductive growth in annual plants. Theor. Popul. Biol. 21, 194-204.

Korasick, D. A., McMichael, C., Walker, K. A., Anderson, J. C., Bednarek, S. Y., and Heese, A. (2010). Novel functions of stomatal cytokinesis-defective 1 (SCD1) in innate immune responses against bacteria. J. Biol. Chem. 285, 23342-23350.

Krol, E., Mentzel, T., Chinchilla, D., Boller, T., Felix, G., Kemmerling, B., Postel, S., Arents, M., Jeworutzki, E., Al-Rasheid, K. A. S., Becker, D., and Hedrich, R. (2010). Perception of the Arabidopsis danger signal peptide 1 involves the pattern recognition receptor AtPEPR1 and its close homologue AtPEPR2. J. Biol. Chem. 285, 13471-13479.

Kwezi, L., Meier, S., Mungur, L., Ruzvidzo, O., Irving, H., and Gehring, C. (2007). The Arabidopsis thaliana brassinosteroid receptor (AtBRI1) contains a domain that functions as a guanylyl cyclase in vitro. PLOS ONE 2, e449. doi: 10.1371/journal.pone.0000449

Laluk, K., Luo, H., Chai, M., Dhawan, R., Lai, Z., and Mengiste, T. (2011). Biochemical and genetic requirements for function of the immune response regulator BOTRYTISINDUCED KINASE1 in plant growth, ethylene signaling, and PAMP-triggered immunity in 
Arabidopsis. Plant Cell 23, 28312849.

Lee, H. Y., Bowen, C. H., Popescu, G. V., Kang, H.-G., Kato, N., Ma, S., Dinesh-Kumar, S., Snyder, M., and Popescu, S. C. (2011). Arabidopsis RTNLB1 and RTNLB2 reticulonlike proteins regulate intracellular trafficking and activity of the FLS2 immune receptor. Plant Cell 23, 3374-3391.

Lee, S.-W., Han, S.-W., Sririyanum, M., Park, C.-J., Seo, Y.-S., and Ronald, P. C. (2009). A Type Isecreted, sulfated peptide triggers XA21-mediated innate immunity. Science 326, 850-853.

Lehti-Shiu, M. D., Zou, C., Hanada, K., and Shiu, S.-H. (2009). Evolutionary history and stress regulation of plant receptor-like kinase/Pelle genes. Plant Physiol. 150, 12-26.

Lerouge, P., Roche, P., Faucher, C., Maillet, F., Truchet, G., Promé, J. C., and Dénarié, J. (1990). Symbiotic host-specificity of Rhizobium meliloti is determined by a sulphated and acylated glucosamine oligosaccharide signal. Nature 344, 781-784.

Li, J., Wen, J., Lease, K. A., Doke, J. T., Tax, F. E., and Walker, J. C. (2002). BAK1, an Arabidopsis LRR receptorlike protein kinase, interacts with BRI1 and modulates brassinosteroid signaling. Cell 110, 213-222.

Lu, D., Lin, W., Gao, X., Wu, S., Cheng, C., Avila, J., Heese, A., Devarenne, T. P., He, P., and Shan, L. (2011). Direct ubiquitination of pattern recognition receptor FLS2 attenuates plant innate immunity. Science 332, 1439-1442.

Lu, D., Wu, S., Gao, X., Zhang, Y., Shan, L., and He, P. (2010). A receptorlike cytoplasmic kinase, BIK1, associates with a flagellin receptor complex to initiate plant innate immunity. Proc. Natl. Acad. Sci. U.S.A. 107, 496-501.

Mithoe, S. C., Boersema, P. J., Berke, L., Snel, B., Heck, A. J. R., and Menke, F. L. H. (2011). Targeted quantitative phosphoproteomics approach for the detection of phospho-tyrosine signaling in plants. J. Proteome Res. 11, 438-448.

Miya, A., Albert, P., Shinya, T., Desaki, Y., Ichimura, K., Shirasu, K., Narusaka, Y., Kawakami, N., Kaku, H., and Shibuya, N. (2007). CERK1, a LysM receptor kinase, is essential for chitin elicitor signaling in Arabidopsis. Proc. Natl. Acad. Sci. U.S.A. 104, 19613-19618.

Molinari, M., and Helenius, A. (2000). Chaperone selection during glycoprotein translocation into the endoplasmic reticulum. Science 288, 331-333.
Nekrasov, V., Li, J., Batoux, M., Roux, M., Chu, Z.-H., Lacombe, S., Rougon, A., Bittel, P., Kiss-Papp, M., Chinchilla, D., van Esse, H. P., Jorda, L., Schwessinger, B., Nicaise, V., Thomma, B. P., Molina, A., Jones, J. D., and Zipfel, C. (2009). Control of the pattern-recognition receptor EFR by an ER protein complex in plant immunity. EMBO J. 28, 34283438.

Nibau, C., and Cheung, A. Y. (2011). New insights into the functional roles of CrRLKs in the control of plant cell growth and development. Plant Signal. Behav. 6, 655-659.

Palma, K., Thorgrimsen, S., Malinovsky, F. G., Fiil, B. K., Nielsen, H. B., Brodersen, P., Hofius, D., Petersen, M., and Mundy, J. (2010). Autoimmunity in Arabidopsis acd11 is mediated by epigenetic regulation of an immune receptor. PLoS Pathog. 6, e1001137. doi: 10.1371/journal. ppat.1001137

Park, C.-J., Bart, R., Chern, M., Canlas, P. E., Bai, W., and Ronald, P. C. (2010a). Overexpression of the endoplasmic reticulum chaperone $\mathrm{BiP} 3$ regulates XA21-mediated innate immunity in rice. PLOS ONE 5, e9262. doi: 10.1371/journal. pone.0009262

Park, C.-J., Han, S.-W., Chen, X., and Ronald, P. C. (2010b). Elucidation of XA21-mediated innate immunity. Cell. Microbiol. 12, 1017-1025.

Park, C.-J., Peng, Y., Chen, X., Dardick, C., Ruan, D., Bart, R., Canlas, P. E., and Ronald, P. C. (2008). Rice $\mathrm{XB15}$, a protein phosphatase $2 \mathrm{C}$, negatively regulates cell death and XA21mediated innate immunity. PLoS Biol. 6, e231. doi: 10.1371/journal. pbio.0060231

Park, C.-J., and Ronald, P. C. (2012). Ligand induced cleavage and nuclear localization of the rice XA21 immune receptor. Nature Precedings. Available at: http://hdl.handle.net/10101/ npre.2012.6776.1.

Petutschnig, E. K., Jones, A. M. E., Serazetdinova, L., Lipka, U., and Lipka, V. (2010). The lysin motif receptorlike kinase (LysM-RLK) CERK1 is a major chitin-binding protein in Arabidopsis thaliana and subject to chitin-induced phosphorylation. J. Biol. Chem. 285, 28902-28911.

Postel, S., Küfner, I., Beuter, C., Mazzotta, S., Schwedt, A., Borlotti, A., Halter, T., Kemmerling, B., and Nürnberger, T. (2010). The multifunctional leucine-rich repeat receptor kinase BAK1 is implicated in Arabidopsis development and immunity. Eur. J. Cell Biol. 89, 169-174.
Qi, Z., Verma, R., Gehring, C., Yamaguchi, Y., Zhao, Y., Ryan, C. A., and Berkowitz, G. A. (2010). $\mathrm{Ca}^{2+}$ signaling by plant Arabidopsis thaliana Pep peptides depends on AtPepR1, a receptor with guanylyl cyclase activity, and cGMP-activated Ca2 + channels. Proc. Natl. Acad. Sci. U.S.A. 107, 21193-21198.

Roux, M., Schwessinger, B., Albrecht, C., Chinchilla, D., Jones, A., Holton, N., Malinovsky, F. G., Tör, M., de Vries, S., and Zipfel, C. (2011). The Arabidopsis leucine-rich repeat receptor-like kinases BAK1/SERK3 and BKK1/SERK4 are required for innate immunity to hemibiotrophic and biotrophic pathogens. Plant Cell 23, 2440-2455.

Saijo, Y., Tintor, N., Lu, X., Rauf, P., Pajerowska-Mukhtar, K., Häweker, H., Dong, X., Robatzek, S., and Schulze-Lefert, P. (2009). Receptor quality control in the endoplasmic reticulum for plant innate immunity. EMBO J. 28, 3439-3449.

Salomon, S., and Robatzek, S. (2006). Induced endocytosis of the receptor kinase FLS2. Plant Signal. Behav. 1, 293-295.

Schulze, B., Mentzel, T., Jehle, A. K. Mueller, K., Beeler, S., Boller, T., Felix, G., and Chinchilla, D. (2010). Rapid heteromerization and phosphorylation of ligand-activated plant transmembrane receptors and their associated kinase BAK1. J. Biol. Chem. 285, 9444-9451.

Schwessinger, B., Roux, M., Kadota, Y., Ntoukakis, V., Sklenar, J., Jones, A., and Zipfel, C. (2011). Phosphorylation-dependent differential regulation of plant growth, cell death, and innate immunity by the regulatory receptor-like kinase BAK1. PLoS Genet. 7, e1002046. doi: 10.1371/journal.pgen.1002046

Seo, Y.-S., Chern, M., Bartley, L. E., Han, M., Jung, K.-H., Lee, I., Walia, H., Richter, T., Xu, X., Cao, P., Bai, W., Ramanan, R., Amonpant, F., Arul, L., Canlas, P. E., Ruan, R., Park, C. J., Chen, X., Hwang, S., Jeon, J. S., and Ronald, P. C. (2011). Towards establishment of a rice stress response interactome. PLoS Genet. 7, e1002020. doi: 10.1371/journal.pgen.1002020

Shah, K., Russinova, E., Gadella, T. W. J. Jr, Willemse, J., and De Vries, S. C. (2002). The Arabidopsis kinase-associated protein phosphatase controls internalization of the somatic embryogenesis receptor kinase 1. Genes Dev. 16, 17071720.

Shimizu, T., Nakano, T., Takamizawa, D., Desaki, Y., Ishii-Minami, N.,
Nishizawa, Y., Minami, E., Okada, K., Yamane, H., Kaku, H., and Shibuya, N. (2010). Two LysM receptor molecules, CEBiP and OsCERK1, cooperatively regulate chitin elicitor signaling in rice. Plant J. 64, 204-214.

Shiu, S.-H., and Bleecker, A. B. (2001). Plant receptor-like kinase gene family: diversity, function, and signaling. Sci. STKE 2001, re22.

Shiu, S.-H., Karlowski, W. M., Pan, R., Tzeng, Y.-H., Mayer, K. F. X., and Li, W.-H. (2004). Comparative analysis of the receptor-like kinase family in Arabidopsis and rice. Plant Cell 16, 1220-1234.

Song, W.-Y., Wang, G.-L., Chen, L.L., Kim, H.-S., Pi, L.-Y., Holsten, T., Gardner, J., Wang, B., Zhai, W.X., Zhu, L.-H., Fauquet, C., and Ronald, P. (1995). A receptor kinaselike protein encoded by the rice disease resistance gene, Xa21. Science 270, 1804-1806.

Stone, J. M., Trotochaud, A. E., Walker, J. C., and Clark, S. E. (1998). Control of meristem development by CLAVATA1 receptor kinase and kinase-associated protein phosphatase interactions. Plant Physiol. 117, 1217-1225.

Suarez-Rodriguez, M. C., AdamsPhillips, L., Liu, Y., Wang, H., Su, S.-H., Jester, P. J., Zhang, S., Bent, A. F., and Krysan, P. J. (2007). MEKK1 is required for flg22-induced MPK4 activation in Arabidopsis plants. Plant Physiol. 143, 661-669.

Sultan, S. E. (2000). Phenotypic plasticity for plant development, function and life history. Trends Plant Sci. 5, 537-542.

Sun, W., Cao, Y., Jansen, K. L., Bittel, P., Boller, T., and Bent, A. F. (2012). Probing the Arabidopsis flagellin receptor: FLS2-FLS2 association and the contributions of specific domains to signaling function. Plant Cell 24, 1096-1113.

Veronese, P., Nakagami, H., Bluhm, B., AbuQamar, S., Chen, X., Salmeron, J., Dietrich, R. A., Hirt, H., and Mengiste, T. (2006). The membraneanchored BOTRYTIS-INDUCED KINASE1 plays distinct roles in Arabidopsis resistance to necrotrophic and biotrophic pathogens. Plant Cell 18, 257-273.

Wan, J., Zhang, X.-C., Neece, D., Ramonell, K. M., Clough, S., Kim, S.-Y., Stacey, M. G., and Stacey, G. (2008). A LysM receptor-like kinase plays a critical role in chitin signaling and fungal resistance in Arabidopsis. Plant Cell 20, 471-481.

Wang, Y.-S., Pi, L.-Y., Chen, X., Chakrabarty, P. K., Jiang, J., De Leon, 
A. L., Liu, G.-Z., Li, L., Benny, U., Oard, J., Ronald, P. C., and Song, W. Y. (2006). Rice XA21 binding protein 3 is a ubiquitin ligase required for full Xa21-mediated disease resistance. Plant Cell 18, 3635-3646.

Wang, Z., Meng, P., Zhang, X., Ren, D., and Yang, S. (2011). BON1 interacts with the protein kinases BIR1 and BAK1 in modulation of temperature-dependent plant growth and cell death in Arabidopsis. Plant J. 67, 1081-1093.

Wiermer, M., Feys, B. J., and Parker, J. E. (2005). Plant immunity: the EDS1 regulatory node. Curr. Opin. Plant Biol. 8, 383-389.

Williams, R. W., Wilson, J. M., and Meyerowitz, E. M. (1997). A possible role for kinase-associated protein phosphatase in the Arabidopsis CLAVATA1 signaling pathway. Proc. Natl. Acad. Sci. U.S.A. 94, 1046710472.

Willmann, R., Lajunen, H. M., Erbs, G., Newman, M.-A., Kolb, D., Tsuda, K., Katagiri, F., Fliegmann, J., Bono, J.-J., Cullimore, J. V., Jehle, A. K., Götz,
F., Kulik, A., Molinaro, A., Lipka, V., Gust, A. A., and Nürnberger, T. (2011). Arabidopsis lysin-motif proteins LYM1 LYM3 CERK1 mediate bacterial peptidoglycan sensing and immunity to bacterial infection. Proc. Natl. Acad. Sci. U.S.A. 108, $19824-$ 19829.

Wong, H. L., Pinontoan, R., Hayashi, K., Tabata, R., Yaeno, T., Hasegawa, K., Kojima, C., Yoshioka, H., Iba K., Kawasaki, T., and Shimamoto, K. (2007). Regulation of rice NADPH oxidase by binding of Rac GTPase to its N-terminal extension. Plant Cell 19, 4022-4034.

Xu, W., Wang, Y., Liu, G., Chen, X. Tinjuangjun, P., Pi, L., and Song, W. (2006). The autophosphorylated Ser686, Thr688, and Ser689 residues in the intracellular juxtamembrane domain of XA21 are implicated in stability control of rice receptor-like kinase. Plant J. 45, 740-751.

Yamaguchi, Y., Pearce, G., and Ryan, C. A. (2006). The cell surface leucine-rich repeat receptor for AtPep1, an endogenous peptide elicitor in Arabidopsis, is functional in transgenic tobacco cells. Proc. Natl. Acad. Sci. U.S.A. 103, 10104-10109.

Zhang, J., Li, W., Xiang, T., Liu, Z., Laluk, K., Ding, X., Zou, Y., Gao, M., Zhang, X., Chen, S.,Mengiste, T., Zhang, Y., and Zhou, J. M. (2010). Receptor-like cytoplasmic kinases integrate signaling from multiple plant immune receptors and are targeted by a Pseudomonas syringae effector. Cell Host Microbe 7, 290-301.

Zhang, Z., Wu, Y., Gao, M., Zhang, J., Kong, Q., Liu, Y., Ba, H., Zhou, J., and Zhang, Y. (2012). Disruption of PAMP-induced MAP kinase cascade by a Pseudomonas syringae effector activates plant immunity mediated by the NB-LRR protein SUMM2. Cell Host Microbe 11, 253-263.

Zipfel, C., Kunze, G., Chinchilla, D. Caniard, A., Jones, J. D. G., Boller, T., and Felix, G. (2006). Perception of the bacterial PAMP EF-Tu by the receptor EFR restricts Agrobacteriummediated transformation. Cell 125, 749-760.
Conflict of Interest Statement: The authors declare that the research was conducted in the absence of any commercial or financial relationships that could be construed as a potential conflict of interest.

Received: 03 May 2012; paper pending published: 01 June 2012; accepted: 16 August 2012; published online: 24 August 2012.

Citation: Greeff C, Roux M, Mundy $J$ and Petersen M (2012) Receptor-like kinase complexes in plant innate immunity. Front. Plant Sci.3:209. doi: 10.3389/ fpls.2012.00209

This article was submitted to Frontiers in Plant Proteomics, a specialty of Frontiers in Plant Science.

Copyright (C) 2012 Greeff, Roux, Mundy and Petersen. This is an open-access article distributed under the terms of the Creative Commons Attribution License, which permits use, distribution and reproduction in other forums, provided the original authors and source are credited and subject to any copyright notices concerning any third-party graphics etc. 